\title{
Fear, Fur, Fauna, Falling: Into Bed with The Lion, the Witch and the Wardrobe
}

\author{
Alan Read
}

A note on the text. Alan Read's contribution to 'The Lion, the Wirch and the Wardrobe: Fifty Years On' was a perfomance in which a version of this paper was delivered in conjunction with a synchronised video montage which variously extended, complemented and commented on the ideas he presented. While it is not possible to find a textual equivalent for the video-text and performance elements which played such a substantial role in the penultimate session of the day, we have tried to retain a flavour of the experience when translating performance into texi.

In several places the paper alludes to two major court cases involving child murders which were in the forefront of British public consciousness when it was evolving. The first involved the infamous abduction, from a busy shopping precinct in Liverpool. and murder in 1993 of 1oddler lames Bulger by two ten-year-old boys. The boys, Robert Thompson and Jon Venables, were being considered for release at the time of the conference. provoking widespread and heated debate. Shorlly before. while Alan was reading The Lion, the Witch and the Wardrobe to his daughter, the body of eight-year-old Sarah Payne was found after many days of searching. The media was preoccupied with her abduction and in particular the distress of her siblings, who had been playing with her moments before she disappeared, taken by the driver of the white van referred to in the text. Coincidentally. the case came to trial at the time the paper was being was being written.

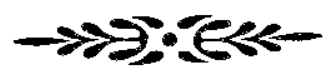

I'm a kidnapper for her, that's what l am. Look at me. Daughter of Eve. Would you believe that I' $m$ the sort of Faun to meet a poor innocent child in the wood, one that had never done any harm, and pretend to be friendly with it, and invite it home to my cave, all for the sake of lulling it to sleep and then handing it over to the White Witch?

"No" said Lucy. "I'm sure you wouldn't do anything of the sort."

(Lewis 1977. p.23)
B ut / would. I am reading this to my six-year-old daughter. Florence. I have lulied my child to sleep: a stupefied condition, a brief period of intermission or quiescence in a storm. I mistake the lull for a calm. My paternal speech, my rendering of this tale, delivers this child in false security to an active state of being - not the dream world beloved of Freud and his followers, but the sleep site of the child at night. That state of apparent unconsciousness, shared by children and other animals, is produced during periods when the nervous system is suspended; interestingly, its various lexical combinations - sleep movement, sleep walking. sleep talking. sleep palsy, sleep waker, sleep sick suggest a multitude of states beyond the baroque of dreams but before the consciousness of waking. As she goes, imperceptibly Florence's eyes flicker with the recognition of a betrayal.

I am singing my child to sleep. A lullaby, literally: 'Lullabye-bye'. This is a farewell and goodnight that must surely mimic a common scene in the bourgeois home not specifically the reading of C.S. Lewis, but the evoking of an ambivalent state produced by listening and luiling that effects the passage from bed time to sleep space. Why ambivalent? Taking the case of Lewis as an example, who could be confident as regards what part of The Lion. the Witch and the Wardrobe was heard, and what was not heard, missed in sleep? Who could know, given these distracted conditions of production, what understanding there is of this tale? What might we speculate is the ambiguous ioss that such reading-into-sleep implies for child literature - a fragmentary accretion of effects, memories and forgettings that are not so much a trauma as an index of child departures from the adult scene? It is this index I would like to add to here, for in the margins of this 'scene', comprising a relationship between an adult and a child, reading and listening, I have become aware of the haunting sense of a performance.

\section{Fear}

We might begin with that extreme loss of the child in sleep - or 'kid-napping': the stealing or carrying off of children in order to provide servants or labourers in the plantations. In the not too distant past, ships would stop at Ireland on their way to Virginia, bringing white servants, 
or 'Kids' as they were called, for four to five years hard labour. In this etymology we might discern just one of the many infant violences that bind the treatment of children to the languages that describe them. The ' $\mathrm{kid}$ on the block' is always and already the object choice of a circulatory adult economy that inscribes the child for the purposes of lubricating its profitable return. A 'kidnapper' - a stealer of human beings, thieves of human flesh, a decoy or spiriter away of young children - disrupts this discreet profitability by making material the uneasy presence of the child in an otherwise adult realm of goods and services.

The unnerving presence of a drifting, spectral, white van on the outskirts of a child's territory of play, conjured up in the UK in countless accounts of siblings who have witnessed the loss of their playmate to an abductor, marks out a horizon in the landscape between familiarity and threat. This demonically neutral vehicie appears, reappears and disappears throughout the nights of my reading as though to reinforce a reluctant passage between my sense of this tale and my daughter's. It has now returned in the narrative of a court case that binds this writing to that reading. one year on. a steam-cleaned screen on which a flickering memory of a child's face has been washed away.

The index of the obscene, that which is literally 'offscene', at one fearful remove but nevertheless bound to any night reading between parent and child, lengthens. It is not as though this index does not have a history. Beneath the Mothercare sign a boy clenches the hand of a smaller boy and walks into the forest of shopping mall neon. In the Radio Rentals television store window, the continuous 625 lines of banality and sensual brutality flicker out. As Kilroy. Feltz and their North American and Australian counterparts in mid-afternoon media Mogadon work up their maternal audiences with a fetishistic blend of anguish and gossip. a small tragedy is unfolding. Jon, or is it Robert? - it is hard to tell from the CCTV cameras that are meant to protect through forensic detail - and Jamie are walking towards a subterranean sign, away from the care of his mother. to a twilight February world above, where not one of the seventeen witnesses to bullying will ask. "Where are you taking this boy who is crying?". Their journey, perhaps inevitably, brings them to a railway line where... where what? What sense can we make of an act that is only complete when its perpetrators express their surprise that new batteries could not revive their victim? And how can this sensemaking be illuminated by a story in which a half animal/ half man expresses his guilt over his intended handing of an innocent child to a White Witch? In short. what sense might we find within fictions of child seduction to aid our understanding of these lost lives?

The first response from the crowd (that Kierkegaard would have referred to as a 'herd') outside the court, fed by the tabloid press, involves the projection of animality onto humanity, as expressed in the strangely contradictory hurling of abuse as the police vehicle transporting the accused speeds by: 'Anima!!'. This is not perhaps surprising, as from childhood and through childhood. those who are least 'response-able' are most closely associated with their animal natures. In this sense. our sense of a child's sense is in the end a curious but obvious form of anthropomorphism. ${ }^{1}$ Not in this instance the reading onto deities of human traits, but nevertheless the residue of assumptions about humans, applied to infant human animals who are not yet in a position to speak for themselves, who, in a contestable sense, are closer to the gentleness of creatures beyond the human-all-too-human

There is a deep ambiguity at work here because we are so unsure as to the limits and boundaries of our own animal species-being, and we require these mediations through language temporarily to still shifting identities. Even though as late as the eighteenth century, European intellectuals were arguing as to whether or not orangutans and chimpanzees should be considered sub-species of mankind, we nevertheless continue skilfully to create socially defined sub-categories of people and then treat the groups so specified as if they were quite different varieties of animal. Among these sub-groups, as a consequence of their being consigned to the far side of an adult/child divide, children are particularly prone to a form of separation that requires anthropomorphic leaps to assign them complex qualities.

This sense of the child somewhere 'out there' is often conveyed in the form of anecdote: in the case of the young 
murderers of Jamie Bulger, the story is peculiarly haunting. caught as it is between the scale model world of the child (flat batteries) and our terror of the technocratic torturer. Anecdotes are ubiquitous to the anthropomorphising process, although there is no clear rationale for why this might be-anecdotes and anthropomorphism do not share any intrinsic or essential binding qualities of definition. But what anecdotes can do exceptionally well within knowledge systems, is to link event and context in peculiarly' forceful way's. For instance, in the 'events' evoked above, in which the perpetrators of uniquely human acts of brutality were inscribed within a familiar zoological rhetoric of animality. we are faced with a conundrum of care. We are confronted with a choice between classifying children (like other animals) as automatons. or granting them volition and information processing capacities. It is obvious that if anthropomorphism w'ere only ' the misattribution of human qualities to animals'. if anthropomorphism were to be characterised by its weakest exemplars, the hideous vocal Americanisation of Winnie-the-Pooh, for example, then few would wish to engage with its methodological challenge. But as Frans de Waal points out:

\section{there is a difference between the use of anthropomorphism for communicatory reasons, or as a tool to generate hypotheses, and anthropomorphism that does little else than project human emotions and intentions onto animals without an attempt at serious investigation.}

(in Mitchell, Thompson \& Miles 1997, p.xiii).

In this sense-making, we are all. of course, projecting backwards and forwards - because by definition we were all children once too. If $I$ am handing Florence in sleep over to the embrace of Tumnus, and then to the White Witch beyond. I am not mimicking the traumas of the events of other children's real lives. traumas such as those described above; I am not simulating those horrors with another fictional horror of animality, good and evil. Rather. I am accentuating in my reading to sleep the very banality, the precious banality. of my daughter, and most daughters relatively untroubled lives. It is this index of difference between the wondrous fiction of the world beyond the wardrobe and the relative static of the world before it that marks out a trajectory of security and adventure for my child - perhaps any child.

The lack of interest 1 have in rushing to a deep reading of the symbolism of this rich literary world (even if 1 were equipped to undertake such a reading) is nurtured by a reciprocal appetite for the surprisingly banal materiality of the world that is left behind. It is in this everyday interface that the resonance of a performance is played out for me. Here, my child joins those who resist the reading of their short lives as 'traumatic'. What happens, Adam Phillips asks, to those of us whose childhoods were "neither lost...nor disturbing... [who had what] we as adults might call the child's "taken for granted" childhood'? (Phillips 2001, pp.13-17) That world, in other words, that is not so much beyond representation as not requiring of representation. Here Adam Phillips' evocation of the child's 'blank' childhood (not repressed, just blank) equates to the child's 'blank' presence sleeping (not dreaming, just sleeping). I might imagine I read to my child to evoke dreams, but my reading is far more likely to bring about a state of beautiful blankness stretching out from Tumnus's tears and guilt over his mission to shop Lucy to the authorities, to a waking state some hours later. a state in which the measure of the narrative of the night before is not so much what is remembered, as that which is happily forgotten.

Can we, as invested as we are in the significance of texts. accept this scale of loss from an economy of reception? The index of this loss is a measure of the performance of a bedtime reading in which the literary model of cause and effect through concentration is supplemented by a falling from listening into hearing in to floating through increasingly heightened states of distraction.

After the schoolroom shootings of Dunblane and Columbine, after the abductions of Jamie and Sarah, the commonest loss expressed was not having said goodbye. I wonder whether the absence of these verbal rites of passage as a child leaves this world (whether temporarily transported by fiction or, like the others I have evoked, permanently through death), this lack of a wave. does not envelop our concern for these children. For after all the 
banality and brutality I describe above, if Emmanuel Levinas is right, that vulnerability is being able to say 'adieu' to this world, there is a small death being played out in each such falling into sleep (Derrida 1995, p.47; 1999). Of course, in French the salutation 'adieu' can as readily signify 'hello', 'I can see you', 'I see that you are there', as the moment of separation, the moment of death. With children, the fear of death cannot be for their life, but the palpable sense of not having lived. And at bedtime, the adieu that marks the passage from here to there is also a giving over to God as in the idiomatic English: goodnight, God-bless.

\section{Fur and fauna}

"You are the child," said Tumnus. "I had orders from the White Witch that if ever I saw a Son of Adam or a Daughter of Eve in the wood, I was to catch them and hand them over to her.... And if I don't," said he, beginning to cry again, "she's sure to find out. And she 'll have my tail cut off. and my horns sawn off, and my beard plucked out, and she'll wave her wand over my beautiful cloven hoofs and turn them into horrid solid hoofs like a wretched horse's. And if she is extra and specially angry she will turn me into stone and I shall be only a statue of a Faun..."

(p.24)

The boards of the wardrobe that Lucy treads are the raked stage for a sequence of anomalous events. Fur and fauna here are images, not metaphors, and hence my resistance to an allegorical reading. For where a surface phenomenon stands as a cipher for uncovering horizon after horizon of otherwise obscure meanings, as it does in so many allegorically driven readings of these resilient texts. codes become superimposed on a point of view that mistakes the distracted tactiiity of experience for the concentrated contemplative individual. ${ }^{2}$ Put bluntly: animals have fur, they do not have leather, and animals don't have meat until they are dead. Fur is apparently left unworked by culture in quite the ways that leather comes to us; it is the raw to leather's cooked. But it is not indigestible for all that. Metaphor gives concrete substance to an impression that is difficult to express. An image, on the other hand, as Gaston Bachelard has shown in The
Poetics of Space (1994), owes its entire being to the imagination and, unlike metaphor, has phenomenological value: it is a phenomenon of being and is specific to the speaking creature.

Lucy confounds the structures of separation that require the anthropomorphic move I have described in the first part of this essay. Her face in the fur resists the reading of separation endorsed by Walter Benjamin when he said,

In an aversion to animals the predominant feeling is fear of being recognized by them through contact. The horror that stirs deep in man is an obscure awareness that in him something lives so akin to the animal that it might be recognized. All disgust is originally disgust at touching.

(Benjamin 1979 p.50)

Not furry contacts. Not touching fur. If Jamie or Sarah had fur, I suspect there would have been an international campaign to protect them; if Dresden or Mostar had fur, likewise. Fur has a cultural politics with values which circulate around not just its commodity nature, as luxury good, article or trade, but also its investment within libidina! desire. Fur carnot be separated from desire.' As both fetish and fashion commodity, fur exists in a field of transactions that mimic those economic spheres within which children make their anomalous presence felt. These transactions invite us to mobilise and negotiate otherwise antagonistic oppositions between child and adult and animal and human

Here the fluidity and permeability of Lewis's tale can be seen in motion. Lucy, for instance, inverts the image of the fur clad bourgeois woman, the White Witch, and also the connections between fur and sex: once prostitutes were forbidden to wear fur to differentiate them from other women, and of course, more prosaically, with the wearing of fur, the inference of bestiality is ever present. The charged ambiguity of being between fur and flesh is a constant. But these are not the associations with fur as worn by the Pevensie children. When Peter, Susan and Edmund. wearing fur coats from the wardrobe, finally enter Narnia in search of Lucy, their furs are described as looking more like 'royal robes than coats' (p.54). This signals that the Witch's reign is over, drawing as it does 
on difference inscribed in European laws of the fifteenth and sixteenth centuries which prevented those of lower classes from acquiring such visual signs of monarchical privilege and therefore challenging the monarchical monopoly over the codes of symbolic power.

So Lucy's passage from here to there is marked by a veritable cacophony' of images, from animal to human. from forest to light. from branches to fur coats and through snow to wooden boards that stage the point of entry and departure between these worlds. In the context of childhood. these boards are, of course, reminiscent of those first stages. built with planks and nails by assiduous care-takers for another Christian rite, the school Nativity play. But how to grant these images the significance they merit without falling into the parallel universe of metaphoric speculation?

These stagings are never innocent. Arnold Van Gennep (1960). the French folklorist and ethnographer, alerted us to the manner in which ancient and tribal societies conceptualised and symbolised the transitions people have to make between well-defined states and statuses if they are to grow up to accommodate themselves to unprecedented and even antithetical conditions. He showed us. as though Lucy's journey lay in front of him. that all rites of transition are marked by three phases: separation, limen or margin, and aggregation. The first phase, when Lucy fails to persuade her siblings of the verity of her journey, comprises symbolic behaviour signifying the detachment of the individual or group, whether from an earlier fixed point in the social structure or from a relatively stable set of cultural conditions. During the intervening liminal phase, the state of the ritual subject becomes ambiguous. In Lucy's case, she passes through a realm or dimension that has few or none of the attributes of the past or coming state, betwixt and between all familiar lines of ciassification. In this second stage. Lucy. and eventually her siblings, don fur coats that announce and accentuate their animality, while discreetly veiling their anomalous nature in the world of hybrids. They are not anomalous in the sense that is concerned with the anormal - that which is outside the rules, or goes against the rules - but because they represent the unequal. the course. the rough, the frayed edge of deterritorialisation for Lucy, a 'furor' as the French theorist Gilles Deleuze would have called her state in a new state. ${ }^{4}$

An anomaly is, of course, not an abnormality - there is nothing jarring in the transition from one world to the other, but a surprising facility and ease of movement that eddies the children to and fro as the narrative proceeds. In The Normal and the Pathological (1989), Georges Canguilhem shows that this diversity does not signify sickness; rather, life is the collection of functions that resist death. If the relation between the environment and the living thing is such that neither can vary without compromising the viability of the living thing irreparably. then the apparent normality of adaptation is in fact pathological. To be sick is to be unable to tolerate change - and Lucy moves between two worlds for which the intolerance to innovation is illuminated by the anomalous. For the anomalous in this narrative is more terrain than bridge between two worlds.

As animals donning skins that enhance their animality, Lucy and her siblings are both pack and individuals. The exceptional individual. in the first instance Lucy, is not the anomalous - the anomalous is a phenomenon that borders these individua!s. In The Lion, the Witch and the Wardrobe, a privileged group of children at play are figured like others identified by Gilles Deleuze and Felix Guattari in their work on those 'becoming animal' including minoritarian groups, the oppressed and prohibited, those in revolt, those on the margins of recognised institutions. In other words, those who constitute a force of relations, a plateau of actions and enthusiasms that are always ambiguous because of the speed with which all societies (and no less Narnia) appropriate their becomings, their becoming animal, their becoming children, to reduce them to totemic or symbolic correspondence (Deleuze \& Guattari 1987).

The antecedents of the Faun were demi-gods, worshipped by the shepherds and farmers on the underside of the nativity, one of the class of rural deities - like men with horns and the tail of a goat, like the satyrs to whom they were assimilated in lustful character. 'Fauna' is a simple application of the name of a rural goddess to the animal 
world in general. Hence Tumnus cries out and confirms himself as animal in the region of Narnia, in the epoch of winter, but he also sheds tears and confirms himself as human in the region beyond the 'wardrobe', just before Christmas. This simple divide along the lines of lacrimosity is just one of the fault lines that separatesthumans from other animals. A handkerchief is passed on and remains in the world of the hybrid to remind us of this confusion, a symbol of surrender to its charm perhaps. As Edmund Leach explains:

Totemism was low and primitive because men and animals were represented as having $a$ confused common origin; animism was likewise low and primitive because it was said to imply that souls inhabit animals and trees just as they inhabit man. But Christianity was high religion because it implies a clear cut discontinuity between ethically conscious human beings and irrational beasts.

(Leach 1982, p.68)

Tears provide the liquidity in this circulating economy between animality and humanity, high and low.

The anomaly of Lucy is not her otherness on arrival in the sameness of the forest, though this of course might account for an acceleration of the pace of the becoming animal that she experiences, but rather the proximity of her becoming 'other than herself' to the animal pack of her aspiration. The pack. herd, community of her family are absent, and in her isolation she is rendered anomalous as the surfaces of one complex enough state of identity, exiled child, become enmeshed with, not just the characteristic traits of a faun - that would have fooled no one-but the affects of the faun. That is, beyond the marks of the species - sounds, movement dynamics and intensities of feeling-lie, not the description of something. but a creature that does something, and through this doing becomes something, somebody - not no-body.

This quality of the anomaious gives Lewis's text as bedtime tale its disturbing feel, like that of a fable, a purity of purpose within a complex context that is unmistakeable when witnessed. but so rare as to make many other bedtime tales pale in comparison. This disturbance is predicated on a set of disruptions to a child's understanding of the place of human animals in nature. This is an anthropomorphic reading that demands a renewed sense of the cultural and historical conventions which determine the shifting place of people in their surroundings. The narrative of Lucy's escapade plays off a set of conventions and constructs of language that presume a point of view within a continuum between child and animal and animal and adult. Without these conventions, this would be less an anthropomorphic view and more an amorphic perspective, a view from nowhere, an unlikely state today in a relativist universe. All descriptions of children and animals are likely to be anthropomorphisms given that there can be no sensible categorical separation of humans from other animals.

The same ambivalences that surround Florence's affinity to other animals surround her uncanny ability to recognise humanness in the material: in the crack of the bedroom ceiling (like Madeleine in her dormitory, for instance), or the sound of intruders in the wind at night. Florence's perceptual responses are not initially driven by what she wants to see. or what is most rational, but by what matters to her most, what has most significance for her now. It is her pressing interests in an ambiguous, uncertain environment (and the twilight between wake and sleep is the most fragile of these contexts) that require her to identify in the unknown the characteristic traits of the human. Her aberrant anthropomorphism is understandable though mistaken. It is, as the Professor would say to Lucy, 'logical' in this sense.

What then might be a way of speaking about this dependency of a child's hearing of an adult's reading? There can be little rationale for an analysis that does not at least characterise this vulnerability if not foreground it as the determining relationship between reader and receiver, father and daughter. Yet, this central and enduring relationship has little credibility in the apparently freefloating domain of texts unhinged from contexts. As the philosopher Alasdair MacIntyre shows, human limitation, dependency and cooperation are not generally acknowledged within philosophical or critical discourses (Macintyre 1999). To harbour these 'conditional' thoughts is what Adam Smith once described as 'splenetic philosophy' (quoted in Machtyre, p.2), and it is within 
this pejorative frame that a theory of 'dependency' appropriate to that of the child-adult reader-relationship is lost.

For Maclntyre, it is clear that this independent fantasy has prevailed. marginalizing thoughts of vulnerability to a philosophical back-water. He believes, as do most philosophers since the advent of phenomenology', that we fail to acknowledge adequately the bodily dimensions of our existence:

This failure of refusal is perhaps rooted in, is certainly reinforced by the extent to which we conceive of ourselves and imagine ourselves as other than animal, as exempt from the hazardous condition of 'mere animality'.

(Macintyre 1999, p.4)

In philosophical (if not in evolutionary) terms, our rationality as thinking beings is somehow independent of our animality -indeed our possibilities for rational thought depend on this breach between humanness and human past. The self-sufficient pretext runs from Aristotle's theory of masculine independent virtues to Adam Smith. Reading here becomes performance by 'proxy', a way of speaking for, and on behalf of, the listening child who is dependent on you and vulnerable to the coming night.

In identifying liminality, Van Gennep discovered a major innovative, transformative dimension of the social that enables us to think through the physical dimension of this performance by proxy. Liminality is not only transition. but also potentiality: not only 'going to be' but also 'what may be'. It therefore has an inherent ethical quality: not what 'is' but what 'ought' to be. Van Gennep might like us to think that Florence undertakes a pilgrimage and a penance on the far side of the banality that is our everyday scene of reading and listening. The fictional route is long, hazardous, beset by robbers, thieves and confidence men a-plenty. as well as by natural dangers and epidemics. Towards the end of this journey, however, the individual's new found freedom from mundane or profane structures is increasingly circumscribed by symbolic structures. Here play and solemnity are equally present. And this is strelv' something Florence would recognise. Play is older than culture, for culture, however inadequately defined, always presupposes human society, and animals like Florence have not waited for humans to teach them how to play. Animals play, so they must be more than mechanical things. Since, following Huizinga, we play know that we play, we must be more than merely rational

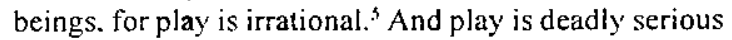
for Florence, especially at bedtime. Maurice Blanchot recognised this when he observed:

Children, whose suspicion that they are constantly being deceived is ever vigilant, show us the connection between games and an uncertain indefinite deception which renders all acts thrilling, solemn and wondrous.

(Blanchot, 1995, p.157)

I wonder whether Florence is feigning sleep. playing at being asleep. I continue reading and day dreaming.

\section{Falling}

"Farewell, Daughter of Eve, "said he. "Perhaps
I may keep the handkerchief?"
"Rather" said Lucy, and then ran towards the far
offpatch of daylight as quickly as her legs would
carryher. Andpresentlyinstead ofrough branches
brushing past her she felt coats, and instead of
crunching snow under her feet she felt wooden
boards, and all at once she found herselfjumping
out of the wardrobe into the same empty room
from which the whole adventure had begun.
(p.26)

Let me conclude in that dark space between fauna and furs where fear gives way to falling, into sleep. A psychoanalytic reading would conceal the depths of these dreams of intimacy, and one is never more aware of the monotony and banality of psychoanalytic frames. of keys and locks, than when approaching the Professor's wardrobe. When we dream of locks and keys there is, as Gaston Bachelard has said. "nothing more to confess' (Bachelard 1994, p.84). But the poetics of this reverie just before sieep extends well beyond psychoanalysis. The looking glass that is on the inside door of the wardrobe, is not there so that we can speculate on the 'mirror stage' of these youngsters who recognise themselves on their return as transformed: children with powers of speech. We are left to make our own day dream, a day-dream that 
remains in the world, that alerts us to the world, that wakes us to the presence, potential and pleasures of reading quietly by a child's face in a low light.

The falling into sleep. borne by narrative, is a crucial corrective to the reverse vertigo of the digital child. Without weight or measure, the idea of nature and the realities it sustains drops away. As Paul Virilio says, "The optical density of the landscape is rapidly evaporating producing confusion between the apparent horizon which is the backdrop of all action and the deep horizon of our collective imagination..." (Virilio 2000, p.22). The wardrobe frames the profound deepening of this confusion in which the territorial body of the child is questioned and the animality of that body erupts. The wardrobe acts as a real time interface that finally, in a parody of instant digital communications to come, replaces the interval that was once responsible for the structuring of history and geography. The Pevensie children finish up, as Virilio says in another context, "in a true culture of the paradox in which everything arrives not only without needing physically to move from one place to another but. more particularly, without having to leave' (Virilio 2000. p. 19). What is called into question here is neither the subjective state of the children nor their objective knowledge of experience, but rather the trajective understanding of 'being in movement', between states and statuses upon which perception of the world depends. Here the narrative couple that Walter Benjamin framed within his essay 'The Storyteller', of the stable productive citizens whose narratives emerge from the place in which they stay, and the traveller who draws stories from places afar, is disturbed by the ubiquity of immediate memory driven by the illumination of real time communications. The wardrobe pre-empts and disturbs our geometry of this loss. For Virilio, the obscuring of the horizon by the square horizon of the screen becomes a 'bug' in our memory of the landscape:

that deep horizon of our memory of places responsible for our orientation in the world causing confusion of near and far, of inside and outside, disorders in common perception that will gravely affect the way we think.

(Viritio 2000, p.26)
How 'thick', might we ask, is the back of the wardrobe between room and world? Here the interval of a passage has become an instantaneous interface in which apparently heavy objects. fur coats for instance, lose their weight and become gossamer covers that are shed like so much reptile skin on return to the human-centric world. The pollution of nature, the whitening of the world by witchcraft, is doubled by the pollution of distances in the tale, the contamination of time that reduces passage from one side to the other in 'no time at all'.

The measure of the 'hard, smooth' (p.13) wardrobe floor is a vector against which to gauge a familiar journey. which for the child is one of discovery compromised by the instantaneous:

Once each generation of human beings had to try and find out how deep the world was for themselves, to free themselves from their familiar neighbourhood and discover distant horizons... In the near future each generation will inherit an optical layer of reality thinned out by the effect of aperspective both fundamentally 'temporal ' and 'atemporal' at the same time. And this will enable them at birth, or as good as - to perceive the end of the world, the narrowness of a habitat instantaneously accessible no matter what the geographical distance.

(Virilio 2000, p.64)

The child remains the last dependable eyewitness to a changing world in which eyesight is doctored by a wild acceleration of the ordinary, the banal and the everyday. After all, Lucy and her brothers and sister arrive back just in time to witness the tourist gaze of the visitors to the Professor's house and become frozen figures in that staged heritage site so distant from those very communications that threaten its historical intransigence: 'ten miles from the nearest railway station and two miles from the nearest post office' (p.9). And with this eyetraining comes the pollution of the subject. the liveliness of the subject, its ability and mobility, the loss of the locomotive body. Just prior to sleep, as though in defiance of seductive lassitude. Florence, as always, undertakes turnings, spins, cartwheels and bows, disequilibrium and reverse-vertigo. disordering balance as a pre-sleep source of pleasure. A way of preparing for listening. 
It is through this dystopic, technologically inverted universe. that Florence falts into sleep through the curiously wooden medium of a volume of rare depth: "1he imner space of an old wardrobe is deep. A wardrobe's inner space is also intimate space. space that is not open in just anybody' (Bachelard 1994, p. 78). It is a space that is open to the child who nestles in its hierarchy of sheets. within what Milosz called its 'mute tumult of memories' (quoted in Bachelard 1994, p.79). As though the world of C.S. Lewis lay beyond his own imaginings, Gaston Bachelard asks of the wardrobe:

\section{If we give objects the friendship they should have. we do not open a wardrobe without a slight start. Beneath its russet wood, a wardrohe is very white almond. To open it is to experience an event of whiteness. \\ (Bachelard 1994, p.81)}

Florence falling into sleep makes a slight start before entering, not Narnia, with its animation. anomalies and animals. she is long gone from there. but the whiteness of just another night, and that will do for now. For this sleep no longer has to be significant for my sake.

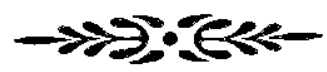

\section{END NOTES}

' My reflections on anthropomorphism draw on Mitchell, Thompson. \& Miles (eds) (1997) Anthropomorphism. Anecdotes and Animals. Albany, State University of New York.

'See Taussig (1992) The Nervous System. London, Routledge, p./47.

"See Masoch (2000) Venus in Furs. London: Penguin: McKenna (1998) Fashion V'ictims. See also Emberley (1998) chapter 2. "The sumptuous details of history' for a fine reading of the political economy of fur.

"See Deleuze \& Guattari, A Thousand Plateaux., especially Becoming - intense, becoming animal. becoming - imperceptible', pp.232309 where the dogmatics of allegoricalty driven psychoanalytic readings of the child and animals are contested by characteristically complex associations of indeterminacy and indiscernibility.

'See Schechner (1993), pp.23-44 for a discussion of the significance of 'playing'.

\section{REFERENCES}

Bacheiard, G. (1994) The Poetics of Space. Boston, Beacon Press.

Benjamin. W. (1979) One-Way Street. London, New Left Books.

Blanchot, M. (1995) 'The Great Hoax' in M. Holland (ed) The Blanchot Reader. Oxford, Blackwell.

Canguithem. G. (1989) The Normal and the Pathological. trans. R.S. Cohen \& C.R. Fawcett, London, Zone Books.

Deleuze, G \& Guattari, F. (1988) A Thousand Plateaux: Capitalism and Schizophrenia, trans. B. Massumi. London, Athlone.

Derrida, J. (1995) The Gift of Death, trans. D. Wills. Chicago, University Press.

Derrida, J. (1999) Adieu to Emmanuel Levinas, trans. P.A. Brautt \& M. Naas. Stanford, University Press.

Emberley, J.V. (1998) Venus and Furs. London. I.B. Tauris.

Leach. E. (1982) 'Humanity and animality', in Social Anthropology. London. Fontana.

Lewis. C.S. (1977) The Lion, the Witch and the Wardrobe. Harmondsworth, Penguin.

MacIntyre, A. (1999) Dependent, Rational Animals: Why Human Beings Need the Virtues. Oxford, Duckworth.

McKenna, C. (1998) Fashion Victims. London. WSPA.

Mitchell, R.W.. Thompson. N.S. \& Miles. H.L. (eds) (1997) Anthropomorphism, Anecdotes and Animals. Albany, State University of New York. 
Phillips, A. (2001) 'Children again', in New Formations, 'The Ruins of Childhood', no. 42. pp. 13-17.

Read, A. (2001) 'Acknowledging the imperative of performance in the infancy of theatre', in Performance Research. 5. 2:61-69.

Schechner. R. (1993) The Future of Ritual. London. Routledge.

Taussig. M. (1992) The Nervous System. London. Routledge.

Van Gennep, A. (1960) [1908] The Rites of Passage. Chicago. University Press.

Virilio. P. (2000) Open Sky, trans. J. Rose. London. Verso.

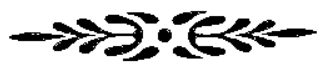

\section{BIOGRAPHICAL NOTE}

Alan Read is Professor of Drama and Theatre Studies at the University of Surrey Roehampton, where his research interests include performance architecture and location, and the presence of children and animals in performance. $\mathrm{He}$ is the author of Theatre and Everyday Life: An Ethics of Performance, and editor of The Fact of Blackness: Frantz Fanon and Visual Representation, and Architecturally Speaking: Practices of Art. Architecture and the Everyday. He is a consultant editor for the journal. Performance Research, and editor of a special edition: 'On Animals', vol. 5, no. 2. He is currently working on a monograph entitled, A Natural History of Performance: Infants, Animals and Other Anomalies. 